The Optimal Adjustment to Liability When Litigation is Costly:A Note Peer-reviewed author version

DE MOT, Jef \& Miceli, Thomas J. (2019) The Optimal Adjustment to Liability When Litigation is Costly:A Note. In: International review of law and economics, 58 (2019), p. 127-131.

DOI: 10.1016/j.irle.2019.03.008

Handle: http://hdl.handle.net/1942/28095 


\title{
The Optimal Adjustment to Liability When Litigation is Costly: A Note
}

\author{
by \\ Jef De Mot* \\ and
}

Thomas J. Miceli**

\begin{abstract}
We show that the optimal liability award with variable litigation costs may be either larger or smaller than the sum of the victim's harm and litigation costs. The reason is that there are two countervailing effects at play. On the one hand, larger damage awards lead to increased litigation expenditures, which have a dampening effect on optimal damages. On the other hand, variable litigation costs only make sense if the parties anticipate a gain from expending litigation effort, which necessarily translates into a probability of plaintiff victory that is less than one. Consequently, the deterrence function of the trial is mitigated, justifying an upward adjustment in the optimal damage award. The optimal adjustment balances these two effects.
\end{abstract}

JEL codes: K13, K41

Key words: Optimal damages, costly litigation, rent seeking

Revised, March 2019

*Department of Economics, University of Hasselt, e-mail: jdemot@yahoo.com.

**Department of Economics, University of Connecticut, Storrs, CT 06269; Ph: (860) 486-5810; e-mail: Thomas.miceli@uconn.edu

We acknowledge the helpful comments of two reviewers, which greatly improved the exposition of this paper. 


\section{The Optimal Adjustment to Liability When Litigation is Costly: A Note}

\section{Introduction}

The economic theory of tort law is based on the premise that liability for accidents forces individuals who are engaged in risky activities to internalize the harm that their actions impose on others. In this way, liability acts like a Pigovian tax. The liability system, however, is a costly means of achieving this goal, as was first pointed out by Shavell (1982). Litigation costs interfere with the goal of risk internalization in two ways: first, they discourage some victims from filing suit, and second, for those cases that are filed, injurers do not account for the trial costs of victims. As a result, injurers are underdeterred relative to a zero-litigation-cost world. The use of a costly liability system to internalize harm is therefore socially desirable only if the deterrence benefits outweigh the costs of operating it.

In light of this conclusion, several authors have examined whether the liability system can be made more efficient by allowing courts to adjust the amount of damages injurers are required to pay. Polinsky and Rubinfeld (1988) first showed that, compared to pure compensatory damages, the optimal adjustment may be positive or negative. Hylton (2002) extended the Polinsky and Rubinfeld results by showing that the optimal liability award under strict liability either equals the sum of the victim's damages and litigation costs, or some lesser amount, depending on the productivity of injurer care. Most recently, Polinsky and Shavell (2014) showed that when plaintiffs and defendants have variable litigation costs-i.e., costs that increase with the damage award- optimal damages are always strictly less than the sum of the victim's harm and litigation costs (assuming lawsuits are desirable at all). The reason is that there is now an additional cost of raising damages at the margin, which must be balanced against the deterrence benefits of any upward adjustment in liability. ${ }^{1}$

This note contributes to this line of literature by showing that the Polinsky and Shavell result does not hold up if account is taken of the reason why litigation costs increase with the damage award. We specifically focus on a model of litigation along the lines of Katz (1988) in which litigants spend more on litigation as the stakes of the case increase. ${ }^{2}$ In that context, we show that the adjustment to liability may be larger or smaller than plaintiffs' total litigation costs. The reason is that in conflict models of this sort, the trial becomes a rent-seeking game in which the plaintiff and defendant fight over the assignment of responsibility for the victim's loss. Thus, the parties expend resources at trial in hopes of obtaining a more favorable ruling from the court: the plaintiff seeks a larger expected judgment and the defendant seeks a smaller one. ${ }^{3}$ It is indeed true that in this context, the Nash-equilibrium levels of expenditure by the parties are increasing in the expected judgment, but it is also true that the plaintiff's expected win rate is generally less than one, for otherwise the defendant would not have invested in the case.

It is this less-than-certain plaintiff win rate that counteracts the result in Polinsky and Shavell (2014). Whereas they showed that variable litigation costs reduce the adjustment of

\footnotetext{
${ }^{1}$ In a recent contribution to this line of literature, Kaplow (2017) examines the optimal structure of private litigation when both the amount of defendant liability and the plaintiff's cost of filing suit can be optimally chosen. This formulation yields very different results from those examined here. For a similar analysis, see Polinsky and Che (1991).

${ }^{2}$ Also see Goodman (1978) and Hause (1989) for similar conflict models of litigation.

${ }^{3}$ In general, it does not matter if the litigation is over the magnitude of damages or the merits of the case, such as whether the defendant caused the accident. All that matters is that the defendant's expected liability is at stake.
} 
damages because of the increase in litigation costs as damages rise, the possibility that the defendant will "win" the case, and hence will avoid some liability, mitigates the deterrence function of the trial, thus justifying an upward adjustment in the optimal damage award. The overall adjustment depends on the relative strengths of these offsetting effects.

\section{The Model}

We use a set-up that closely follows Hylton (2002), except for the variable litigation expenditures. ${ }^{4}$ Let

$x=$ injurer's expenditure on care;

$p(x)=$ probability of an accident, where $p^{\prime}<0$ and $p^{\prime \prime}>0$;

$h=$ harm suffered by victim;

$f(h)=$ density of harm across victims, where $h \in[0, \infty) ;^{5}$

$\delta=$ damages awarded by the court;

$\gamma_{p}, \gamma_{d}=$ fixed litigation costs of the plaintiff (victim), $p$, and defendant (injurer), $d$;

$\lambda_{p}, \lambda_{d}=$ variable litigation costs of the plaintiff and defendant.

We assume the court can observe $h$ in individual cases and hence can condition the award $\delta$ on $h$ (as will be detailed below). Following Katz, we assume that the trial will determine whether or not the defendant is liable for the victim's harm; that is, whether or not he has to pay $\delta$. Thus, the amount of damage in a given case, $h$, is not in dispute.

The outcome of the trial is captured by the conflict success function ${ }^{6}$

$$
\pi\left(\lambda_{p}, \lambda_{d}\right)=\frac{\lambda_{p}}{\lambda_{p}+\theta \lambda_{d}}
$$

which is defined to be the probability that the plaintiff wins. In this expression, the parameter $\theta \geq 0$ reflects the inherent strength of the defendant's case. If $\theta=0$, the plaintiff will win with certainty - this is the implicit assumption in both Hylton (2002) and Polinsky and Shavell (2014) — while at the other extreme, if $\theta \rightarrow \infty$ the defendant wins with certainty (no liability). One interpretation of the intermediate case of $0<\theta<1$ is a dispute over whether the defendant caused the plaintiff's harm under strict liability, or how much of that harm he caused. (Another interpretation could be the extent of injurer negligence, though to properly capture that case we would have to treat $\theta$ as a function of the injurer's care.) In any case, note that the $\pi(\cdot)$ function has the following properties:

$$
\frac{\partial \pi}{\partial \lambda_{p}}>0, \quad \frac{\partial^{2} \pi}{\partial \lambda_{p}^{2}}<0, \quad \frac{\partial \pi}{\partial \lambda_{d}}<0, \quad \frac{\partial^{2} \pi}{\partial \lambda_{d}^{2}}>0
$$

\footnotetext{
${ }^{4}$ One difference from Hylton (2002) is that we do not assume the victim's harm depends on the injurer's care choice. In our formulation, care only reduces the probability of an accident. This difference is purely for simplicity. ${ }^{5}$ Polinsky and Shavell (2014) assume a fixed level of damages for all accidents, which means that either all or no plaintiffs file suit. We note below (see footnote 10) that our more general treatment of damages, following Hylton (2002), is not a driving factor of our results.

${ }^{6}$ See Garfinkel and Skaperdas (2006) for a review of the uses of this type of function.
} 
[Figure 1 here]

The sequence of events is depicted in Figure 1. First, the level of liability for any harm is announced by the court or legislature. This defines the liability function $\delta(h)$ that all subsequent courts must follow. The defendant then chooses his level of care, at which time we assume he does not know the particular plaintiff he will face, though he knows the distribution of $h$. The victim/plaintiff observes her harm and the injurer's care, and then decides whether or not to file suit. If she does file, the parties choose their litigation expenditures, which then determine the outcome of the trial according to (1). We examine these choices using backwards induction.

If a plaintiff of type $h$ files suit, the parties will choose their variable litigation costs to achieve the most favorable outcome at trial. The plaintiff will therefore choose $\lambda_{p}$ to maximize

$$
\pi\left(\lambda_{p}, \lambda_{d}\right) \delta-\lambda_{p}
$$

and the defendant will choose $\lambda_{d}$ to minimize

$$
\pi\left(\lambda_{p}, \lambda_{d}\right) \delta+\lambda_{d}
$$

Deriving the two first-order conditions and solving simultaneously for the Nash equilibrium for the case where $\pi\left(\lambda_{p}, \lambda_{d}\right)$ is given by (1) yields

$$
\lambda_{p}^{*}=\lambda_{d}^{*}=\frac{\theta \delta}{(1+\theta)^{2}}
$$

and

$$
\pi^{*}=\frac{1}{1+\theta}
$$

Thus, it turns out that the litigants choose the same level of expenditure, ${ }^{7}$ and that expenditure is increasing in the amount of liability, conditional on $\theta>0$. The equilibrium is shown graphically in Figure 2 for the case where $0<\theta<1$. In the graph, $\lambda_{p}^{*}\left(\lambda_{d}\right)$ and $\lambda_{d}^{*}\left(\lambda_{p}\right)$ indicate the reaction curves for the plaintiff and defendant, respectively. Note from (6) that the plaintiff's equilibrium win probability depends only on the parameter $\theta$. Further, $\pi^{*}<1$ for $\theta>0$, and $\partial \pi^{*} / \partial \theta<0$. Thus, the stronger is the defendant's case, the lower is the plaintiff's chance of winning.

[Figure 2 here]

At this point, we follow the literature and write the defendant's liability as the sum of compensatory damages and an additive adjustment:

\footnotetext{
${ }^{7}$ This is an artifact of the form of the conflict success function in (1), which is a consequence of its being homogenous of degree zero in the expenditure levels of the two parties (i.e., the fact that multiplying both $\lambda_{p}$ and $\lambda_{d}$ by a positive constant leaves the function unchanged). A more general formulation, such as that suggested by Clark and Riis (1998), would allow asymmetries. However, because our main result depends only on the fact that $\pi^{*}<1$ in equilibrium and not on the particular expenditure levels of the two parties, we retain the simpler formulation.
} 


$$
\delta(h)=h+\varphi
$$

where $\varphi$ will be chosen optimally. This is the simplest possible damage function that the court could employ. Note in particular that the adjustment is assumed to be the same for all plaintiffs regardless of their damages. In other words, $\varphi$ is treated as a parameter rather than itself being a function of $h$. Our results will obviously be sensitive to this specification. ${ }^{8}$

Given (7), a plaintiff of type $h$ will file suit if and only if

$$
\pi^{*}(h+\varphi)-\lambda_{p}^{*} \geq \gamma_{p}
$$

Writing this as an equality, substituting from (5) and (6), and solving for $h$ gives the threshold level of harm that results in a suit:

$$
\bar{h}=\max \left[\gamma_{p}(1+\theta)^{2}-\varphi, 0\right]
$$

Thus, when $\gamma_{p}(1+\theta)^{2}>\varphi$, only those plaintiffs with $h \geq \bar{h}>0$ file suit, whereas when $\gamma_{p}(1+$ $\theta)^{2} \leq \varphi, \bar{h} \equiv 0$ and all plaintiffs file.

Next consider the care choice of defendants. Knowing the liability rule and the distribution of plaintiff types, a defendant will choose care to minimize his private costs:

$$
p(x) \int_{\bar{h}}^{\infty}\left[\pi^{*}(h+\varphi)+\lambda_{d}^{*}+\gamma_{d}\right] f(h) d h+x
$$

Using (5) and (6), this becomes

$$
p(x) \int_{\bar{h}}^{\infty}\left[\frac{(h+\varphi)(1+2 \theta)}{(1+\theta)^{2}}+\gamma_{d}\right] f(h) d h+x
$$

The resulting first-order condition defining the defendant's optimal care, denoted $\hat{x}$, is

$$
p^{\prime}(x) \int_{\bar{h}}^{\infty}\left[\frac{(h+\varphi)(1+2 \theta)}{(1+\theta)^{2}}+\gamma_{d}\right] f(h) d h+1=0
$$

It is easy to verify that $\partial \hat{x} / \partial \varphi>0$. This is true both because an increase in $\varphi$ raises the defendant's liability per accident, and because it induces more plaintiffs to file suit by lowering $\bar{h}$ provided $\bar{h}>0$. In combination these factors represent the deterrent effect of the adjustment to liability.

Social costs in the current model are given by

$$
S C=p(\hat{x})\left[\int_{0}^{\infty} h f(h) d h+\int_{\bar{h}}^{\infty}\left(\lambda_{p}^{*}+\lambda_{d}^{*}+\gamma_{p}+\gamma_{d}\right) f(h) d h\right]+\hat{x}
$$

\footnotetext{
${ }^{8}$ While the treatment of $\varphi$ as a parameter is consistent with both Hylton (2002) and Polinsky and Shavell (2014), it is more consequential here because, unlike Hylton, we are allowing litigation costs to depend on $h$, and unlike Polinsky and Shavell, we are assuming that $h$ varies across plaintiffs.
} 
where the first integral term is total plaintiff harm and the second is expected litigation costs from those accidents that result in suits. The optimal adjustment to liability is found by choosing $\varphi$ to minimize (13), taking account of the effect of $\varphi$ on $\hat{x}, \bar{h}$, and $\lambda_{p}{ }^{*}+\lambda_{d}{ }^{*}$. The derivative of (13) with respect to $\varphi$ yields the overall effect:

$$
\begin{gathered}
\frac{\partial S C}{\partial \varphi}=\left\{p^{\prime}\left[\int_{0}^{\infty} h f(h) d h+\int_{\bar{h}}^{\infty}\left(\lambda_{p}^{*}+\lambda_{d}^{*}+\gamma_{p}+\gamma_{d}\right) f(h) d h\right]+1\right\} \frac{\partial \hat{x}}{\partial \varphi} \\
-p\left(\lambda_{p}^{*}+\lambda_{d}^{*}+\gamma_{p}+\gamma_{d}\right) f(\bar{h}) \frac{\partial \bar{h}}{\partial \varphi} \\
+p \int_{\bar{h}}^{\infty}\left(\frac{\partial \lambda_{p}^{*}}{\partial \varphi}+\frac{\partial \lambda_{d}^{*}}{\partial \varphi}\right) f(h) d h
\end{gathered}
$$

The first term on the right-hand side represents the deterrence benefits of raising $\varphi$, while the second and third terms represent the increase in litigation costs arising from, respectively, the increased number of suits, and the increase in variable litigation expenditures per suit.

To further analyze this derivative, substitute (12) into the first term, and then use (5) and (6) to get

$$
\begin{gathered}
\frac{\partial S C}{\partial \varphi}=p^{\prime}\left\{\int_{0}^{\bar{h}} h f(h) d h+\int_{\bar{h}}^{\infty}\left[h\left(1-\frac{1}{(1+\theta)^{2}}\right)+\gamma_{p}-\frac{\varphi}{(1+\theta)^{2}}\right] f(h) d h\right\} \frac{\partial \hat{x}}{\partial \varphi} \\
-p\left[\frac{2 \theta(h+\varphi)}{(1+\theta)^{2}}+\gamma_{p}+\gamma_{d}\right] f(\bar{h}) \frac{\partial \bar{h}}{\partial \varphi} \\
+p \int_{\bar{h}}^{\infty} \frac{2 \theta}{(1+\theta)^{2}} f(h) d h
\end{gathered}
$$

We begin our analysis by considering the case where $\theta=0$, which produces no variable litigation costs because the plaintiff's probability of winning is identically equal to one (i.e., $\lambda_{p}{ }^{*}=\lambda_{d}{ }^{*}=0$ ). In that case, the final term in (15) drops out, and we have

$$
\frac{\partial S C}{\partial \varphi}=p^{\prime}\left[\int_{0}^{\bar{h}} h f(h) d h+\int_{\bar{h}}^{\infty}\left(\gamma_{p}-\varphi\right) f(h) d h\right] \frac{\partial \hat{x}}{\partial \varphi}-p\left(\gamma_{p}+\gamma_{d}\right) f(\bar{h}) \frac{\partial \bar{h}}{\partial \varphi}
$$

where $\bar{h}=\max \left[\gamma_{p}-\varphi, 0\right]$. This is Hylton's (2002) model, for which he shows that the optimal liability adjustment is such that $\varphi^{*} \leq \gamma_{p}$. Specifically, if care is productive over the entire range of accidents, meaning that it is efficient for all plaintiffs to file, $\bar{h}=0$ at the optimum, and so the final term in (16) drops out because $\partial \bar{h} / \partial \varphi=0$. In that case, setting $\partial S C / \partial \varphi=0$ yields $\varphi^{*}=\gamma_{p}$. If, however, care is not productive over the entire range of harm, the optimum will involve $\bar{h}>0$, and hence $\partial \bar{h} / \partial \varphi<0$. In that case, $\varphi^{*}<\gamma_{p}$ such that the marginal deterrence benefit of the last suit 
filed (the first term on the right-hand side of (16)) equals the marginal cost. In fact, $\varphi^{*}<0$ is possible, meaning that some suits for which $h>\gamma_{p}$ should be barred.

More importantly, Hylton (2002) shows that $\varphi>\gamma_{p}$ can never be an optimum. This is true because setting $\varphi=\gamma_{p}$ induces all plaintiffs to file suit and forces the defendant to internalize plaintiffs' litigation costs. Thus, he chooses the socially optimal level of care, and so raising $\varphi$ any further would result in too much care. Formally, $\varphi>\gamma_{p}$ causes $\partial S C / \partial \varphi>0$.

In their comment on Hylton (2002), Polinsky and Shavell (2014) show that if there are variable litigation costs that increase with the level of defendant liability, the optimal adjustment to liability will be further restricted. In particular, they establish that the adjustment will necessarily be less than the plaintiff's total litigation costs. This is true because there is now an additional marginal cost of raising $\varphi$, which in our model is given by the final term in (15).

We now show that this conclusion may not be true in our model. Specifically, we show that when variable litigation costs are introduced in the manner of Katz (1988), the optimal adjustment may be larger or smaller than the plaintiff's total litigation costs. The reason for this difference is that, given the conflict model of litigation, variable litigation costs only make sense if the parties anticipate a gain from expending effort in litigation, and this effort necessarily translates into a probability of plaintiff victory that is less than one in the Nash equilibrium. This is captured in the above conflict model by $\theta>0$, which, as we have seen, is a necessary condition for the $\lambda_{i}{ }^{*}$ 's to be positive but also implies that $\pi^{*}<1$.

To demonstrate this claim, we set $\varphi$ at the level where all plaintiffs are just willing to file, or $\bar{h}=0$. From (9) this implies that

$$
\varphi=\gamma_{p}(1+\theta)^{2}
$$

In this case, (15) becomes

$$
\left.\frac{\partial S C}{\partial \varphi}\right|_{\varphi=\gamma_{p}(1+\theta)^{2}}=p^{\prime} \int_{0}^{\infty} h\left(1-\frac{1}{(1+\theta)^{2}}\right) f(h) d h \frac{\partial \hat{x}}{\partial \varphi}+p \frac{2 \theta}{(1+\theta)^{2}}
$$

The first term on the right-hand side is negative when $\theta>0$ (given $p^{\prime}<0$ ), indicating that there are still some deterrence benefits from raising $\varphi$. This is true, despite the fact that all plaintiffs are filing suit, because the defendant does not fully internalize all plaintiff damages when $\pi^{*}<1$. Whether or not a further increase in $\varphi$ is socially desirable, however, depends on whether this increase in deterrence offsets the corresponding increase in variable litigation costs, which is given by the second term. Since either of these effects may dominate, we cannot conclude that the optimal adjustment in liability is capped at the level where it just induces all plaintiffs to file suit. That is, $\varphi^{*} \geq \frac{<}{<} \gamma_{p}(1+\theta)^{2}$.

This result shows that $\varphi^{*}$ may exceed the total litigation costs for the plaintiff with the lowest level of damages (zero). ${ }^{9}$ We can further conclude, however, that if the sign of (18) is strictly negative, the optimal adjustment will also be greater than the litigation costs of some plaintiffs with positive damages. In comparing this conclusion to the results of Polinsky and

\footnotetext{
${ }^{9}$ Intuitively, if the least harmed victim $(h=0)$ has a suit with positive expected value, it means that her equilibrium probability of victory augmented by the adjustment is larger than the sum of her fixed and variable litigation costs. And since the equilibrium probability of victory is smaller than 1 , it follows that for $h=0$, the adjustment can be larger than the total litigation costs of the plaintiff.
} 
Shavell (2014), it is important to recall that their model assumed all plaintiffs had the same damages. However, because we have allowed damages to vary across plaintiffs, we cannot make a blanket statement about how the optimal adjustment compares to the litigation costs for the entire population of plaintiffs. At most we can prove that the optimal adjustment may exceed the total litigation costs of some plaintiffs. We formally state this result as follows:

Proposition: When the plaintiff and defendant incur variable costs in litigating over the assignment of liability, and the outcome of the trial is determined by a contest success function, then the optimal adjustment to damages may be larger or smaller than the total litigation costs of plaintiffs. ${ }^{10}$

Proof: We prove this by constructing an example showing that the adjustment can exceed the total litigation costs for at least some plaintiffs. In the example, the probability of an accident is given by $p(x)=1 /(1+x)$, the distribution of victim harm is uniform on $[0,20,000]$, and $\gamma_{p}=100$. Figure 3 graphs the expression in (18) for different values of $\pi^{*}=1 /(1+\theta)$. Note that when $\theta=0$ $\left(\pi^{*}=1\right), \partial S C / \partial \varphi=0$ at $\varphi^{*}=\gamma_{p}$, which is the solution to Hylton's model when it is optimal for all suits to be filed. However, for $\theta>0\left(\pi^{*}<1\right), \partial S C / \partial \varphi$ may be positive, in which case $\varphi^{*}<\gamma_{p}(1+\theta)^{2}$, or negative, in which case $\varphi^{*}>\gamma_{p}(1+\theta)^{2}$. This shows that for $h=0, \varphi^{*}$ may be larger than total litigation costs. We now show that for some $h>0, \varphi^{*}$ may also be larger than total litigation costs. Consider the plaintiff with $h=5,000$. In the example, when $\pi^{*}=.25(\theta=3),(18)$ is negative and so $\varphi^{*}>\gamma_{p}(1+\theta)^{2}=1,600$. Thus, let $\varphi^{*}=1,600+\varepsilon$ for some $\varepsilon>0$. The total litigation costs for the plaintiff with $h=5,000$ are therefore $\lambda_{p}{ }^{*}+\gamma_{p}=1,337.5+0.1875 \varepsilon$, which is clearly less than $\varphi^{*}=1,600+\varepsilon$.

[Figure 3 here]

We further find that as average victim harm increases (i.e., as the upper bound on the distribution of $h$ rises), the range over which $\partial S C / \partial \varphi<0$ expands, reflecting a greater deterrence benefit as accidents become more harmful. Thus, it is more likely that $\varphi^{*}>\gamma_{p}(1+\theta)^{2}$.

As a final point, we note that the result here is related to Png's (1986) demonstration that damages need to be inflated to offset judicial error, which in the current context is reflected by $\pi^{*}<1$. This represents a type-2 error, or false acquittal. ${ }^{11}$ Our model does not allow for type- 1 errors (false convictions), which Png shows may require a subsidy of "legal" behavior. Kaplow's (2017) model of the optimal design of private litigation incorporates both factors, but also allows for additional policy instruments.

\section{Conclusion}

The optimal liability award with variable litigation costs is not necessarily smaller than the sum of the victim's harm and litigation costs. While equilibrium levels of expenditure are

\footnotetext{
${ }^{10} \mathrm{We}$ emphasize that this result is not driven by our assumption of a distribution of plaintiff damages but by the fact that $\pi^{*}<1$ in equilibrium, as dictated by the contest model of litigation. Even if the level of damages were fixed, as long as it is large enough to induce plaintiffs to sue (the only relevant case), the parties will still litigate over how the damages will be allocated, which will result in a less-than-certain probability of plaintiff victory. As a result, the optimal adjustment in damages would need to be increased upward relative to the case where the plaintiff's victory is certain.

${ }^{11}$ This is an error in the sense that we are assuming the injurer is the true cause of the victim's harm but may escape liability as a result of litigation.
} 
increasing in the expected judgment, the plaintiff's equilibrium probability of victory is correspondingly less than one. The former effect works in the direction of decreasing the optimal damage award, while the latter justifies an increase in the award. Because either effect may dominate, we can reach no specific conclusion regarding the optimal adjustment to compensatory damages across the population of plaintiffs. 


\section{References}

Clark, D., \& Riis, C. (1998). Contest success functions, Economic Theory, 11, 201-204.

Garfinkel, M. R. \& Skaperdas, S. (2007). Economics of conflict: an overview. In T. Sandler \& K. Hartley (Eds.), Handbook of Defense Economics (pp. 649-709). New York: Elsevier.

Goodman, J. (1978). An economic theory of the evolution of the common law. Journal of Legal Studies, 7, 393-406.

Hause, J. (1989). Indemnity, settlement, and litigation, or I'll be suing you. Journal of Legal Studies, 18, 157-80.

Hylton, K. N. (2002). Welfare implications of costly litigation under strict liability. American Law and Economics Review, 4, 18-43.

Kaplow, L. (2017). Optimal design of private litigation. Journal of Public Economics, 155, 6473.

Katz, A. (1988). Judicial decisionmaking and litigation expenditure. International Review of Law and Economics, 8, 127-43.

Png, I. (1986). Optimal subsidies and damages in the presence of judicial error. International Review of Law and Economics, 6, 101-105.

Polinsky, A. M. \& Rubinfeld, D. L. (1988). The welfare implications of costly litigation for the level of liability. Journal of Legal Studies, 17, 151-64.

Polinsky, A. M. \& Che, Y. K. (1991). Decoupling liability: optimal incentives for care and litigation. Rand Journal of Economics, 22, 562-570.

Polinsky, A. M. \& Shavell, S. (2014). Costly litigation and optimal damages. International Review of Law and Economics, 37, 86-89.

Shavell, S. (1982). The social versus the private incentive to bring suit in a costly legal system. Journal of Legal Studies, 11, 333-339. 


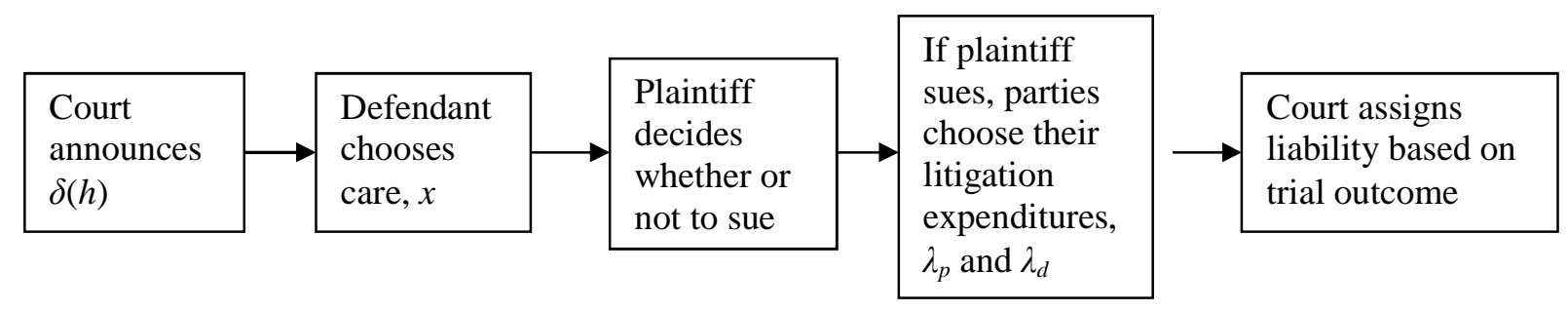

Figure 1. Sequence of events. 


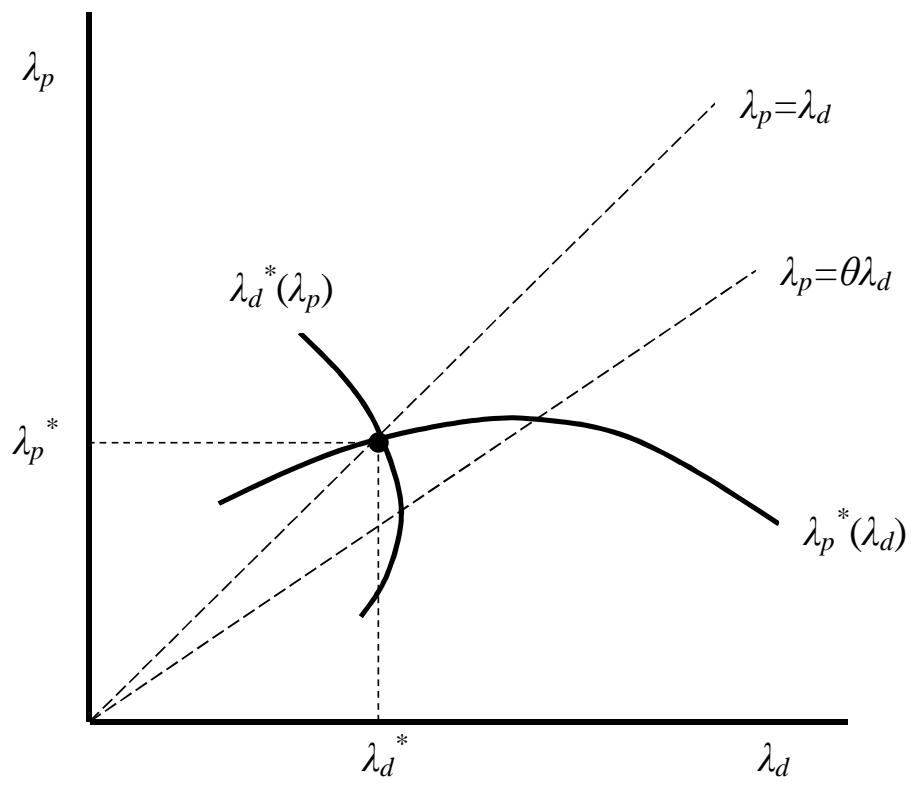

Figure 2. Equilibrium litigation expenditures for the case where $0<\theta<1$. 


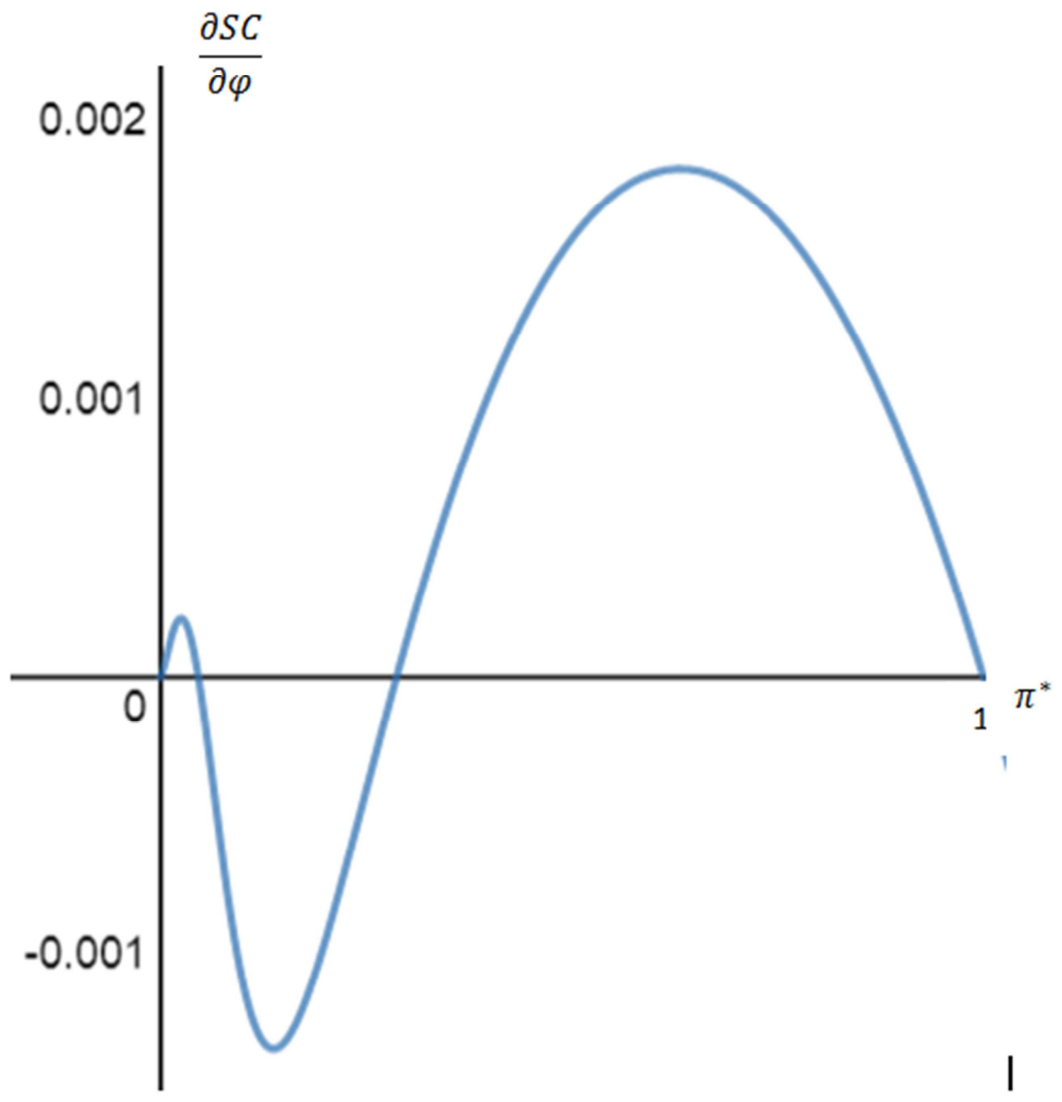

Figure 3. Graph of $\partial S C / \partial \varphi$ as a function of $\pi^{*}=1 /(1+\theta)$ for the case where $\varphi=\gamma_{p}(1+\theta)^{2}$. 